\title{
PENGEMBANGAN MASYARAKAT BERWIRAUSAHA DESA PASAURAN KECAMATAN CINANGKA KABUPATEN SERANG BANTEN
}

\author{
Bambang Hariyanto \\ Universitas Banten Jaya, J1 Syech Nawawi Albantani Serang, Banten, Indonesia \\ Email: bambanghariyanto@unbaja.ac.id
}

\begin{abstract}
Administratively, the area of Pasauran Village consists of 4 (four) Community Associations, and 12 (twelve) Neighborhood Associations. In general, Pasauran Village Typology consists of Rice Fields and Farms. Topographic Pasauran Village in general, including lowland areas, and based on the height of the area Pasauran Village is classified to (lowlands $(0-100 \mathrm{~m}$ above sea level). The total population of Pasauran Village. Based on the Village Profile in 2018 there were 2,957 people consisting of 1,525 men and 1,432 women. The main source of income of the population is from agriculture. Land conditions in Serang Regency are divided into two parts, namely protected areas and cultivation areas. In implementing Thematic KKM in Pasauran Village, KKM students are expected to be able to make programs and strategic plans related to the development of tourism and entrepreneurship areas in Pasauran Village. In addition, KKM students are also expected to be able to realize the tri darma of higher education especially in the fields of entrepreneurship, education and culture in the area.
\end{abstract}

Keywords: Pasauran Village; Entrepreneurship; Culture.

\begin{abstract}
ABSTRAK
Secara Administratif, wilayah Desa Pasauran terdiri dari 4 (empat) Rukun Warga, dan 12 (dua belas) Rukun Tetangga. Secara umum Tipologi Desa Pasauran terdiri dari Persawahan dan Perladangan. Topografis Desa Pasauran secara umum termasuk daerah dataran rendah, dan berdasarkan ketinggian wilayah Desa Pasauran diklasifikasikan kepada (dataran rendah $(0-100 \mathrm{~m}$ dpl). Jumlah Penduduk Desa Pasauran. berdasarkan Profil Desa tahun 2018 sebanyak 2.957 jiwa yang terdiri dari 1.525 laki laki dan 1.432 perempuan. Sumber penghasilan utama penduduk dari Pertanian. Kondisi lahan di kabupaten Serang terbagi menjadi dua bagian yaitu kawasan lindung dan kawasan budidaya. Dalam pelaksanaan KKM Tematik di Desa Pasauran mahasiswa KKM diharapkan mampu membuat program-program maupun perencanaan-perencanaan strategis yang berkaitan dengan pengembangan daerah wisata dan kewirausahaan di Desa Pasauran. Selain itu, mahasiswa KKM juga diharapkan mampu mewujudkan tri darma perguruan tinggi terutama dalam bidang kewirausahaan, pendidikan dan budaya di daerah tersebut.
\end{abstract}

Kata Kunci: Desa Pasauran; Kewirausahaan; Budaya.

\section{PENDAHULUAN}

Desa Pasauran merupakan salah satu desa di Kecamatan Cinangka Kabupaten Serang, Provinsi Banten, memilik luas 100.40 Ha, Secara geografis Desa Pasauran berbatasan dengan wilayah sebagai berikut :

1. Sebelah Utara, berbatasan dengan Desa Bulakan

2. Sebelah Timur, berbatasan dengan Desa Bantarwangi

3. Sebelah Selatan, berbatasan dengan Desa Umbul Tanjung

4. Sebelah Barat, Berbatasan dengan Selat Sunda 
Secara Administratif, wilayah Desa Pasauran terdiri dari 4 (empat) Rukun Warga, dan 12 (dua belas) Rukun Tetangga. Secara umum Tipologi Desa Pasauran terdiri dari Persawahan dan Perladangan. Topografis Desa Pasauran secara umum termasuk daerah dataran rendah, dan berdasarkan ketinggian wilayah Desa Pasauran diklasifikasikan kepada (dataran rendah (0 100 m dpl). Jumlah Penduduk Desa Pasauran. berdasarkan Profil Desa tahun 2018 sebanyak 2.957 jiwa yang terdiri dari 1.525 laki laki dan 1.432 perempuan. Sumber penghasilan utama penduduk dari Pertanian.

KKM TEMATIK-UNBAJA adalah suatu bentuk pendidikan dengan cara memberikan pengalaman belajar kepada mahasiswa di tengah-tengah kehidupan masyarakat, dengan secara nyata turut membantu menyelesaikan masalah masyarakat berdasarkan kompetensi keilmuan mahasiswa. Kompetensi di sesuaikan dengan situasi, kondisi, masalah, dan priortas kebutuhan masyarakat. Di lapangan dengan pendekatan interdisipliner dan ilmiah. Kegiatan pengelolaan KKM TEMATIK-UNBAJA tidak saja menjamin diperolehnya pengalaman belajar melakukan kegiatan pembangunan masyarakat secara konkrit yang bermanfaat bagi mahasiswa dan masyarakat di mana mereka di tempatkan. Dalam pembuatan pemograman KKM TEMATIKUNBAJA harus didasari atas sinkronisasi atau sinergisitas antara masalah apa yang ada dalam masyarakat dengan kompetensi mahasiswa.

KKM merupakan mata kuliah wajib tempuh di Universitas Banten Jaya yang memiliki tujuan yaitu:

1. Meningkatkan sikap empati dan kepeulian mahasiswa terhadap masyarakat beserta problematikanya

2. Melaksanakan kemampuan hard skill dan soft skill yang telah di pelajari di kampus secara team work dan interdisipliner

3. Menanamkan nilai kepribadian : nasionalisme dan jiwa pancasialis, keulatan, etos kerja dan tanggung jawab, kemandirian, kepemimpinan dan kewirausahaan.

4. Meningkatkan daya saing bangsa

5. Menanamkan jiwa : eksploratif dan analitis, learning community dan learning sociality

Pencapaian ketiga tujuan tersebut penyusun melaksanakan berbagai kegiatan yang diawali dengan observasi melihat situasi dan kondisi masyarakat yang ada sesuai dengan berbagai pertimbangan, masukan, saran dan arahan dari berbagai elemen masyarakat. Universitas Banten Jaya melalui Lembaga Pengembangan, Penelitian, dan Pengabdian Pada Masyarakat (LP3M) bekerjasama dengan Pemerintah Kabupaten Serang melalui Dinas Koperasi, Perindustrian dan Perdagangan mengadakan KKM Tematik UNBAJA untuk wilayah Kabupaten Serang. Mahasiswa KKM di Kabupaten Serang diharapkan membantu Dinas Koperasi, Perindustrian dan Perdagangan Kabupaten Serang untuk mengembangkan daerah- 
daerah setempat, khususnya desa Pasauran yang ada di Kecamatan Cinangka, Kabupaten Serang.

Kabupaten Serang merupakan salah satu dari delapan kabupaten/kota di Propinsi Banten, terletak diujung barat bagian utara pulau jawa dan merupakan pintu gerbang utama yang menghubungkan pulau Sumatera dengan pulau Jawa dengan jarak kurang lebih $70 \mathrm{KM}$ dari Jakarta, Ibukota negara Indonesia. Kondisi lahan di kabupaten Serang terbagi menjadi dua bagian yaitu kawasan lindung dan kawasan budidaya. Dalam pelaksanaan KKM Tematik di Desa Pasauran mahasiswa KKM diharapkan mampu membuat program-program maupun perencanaan-perencanaan strategis yang berkaitan dengan pengembangan daerah wisata dan kewirausahaan di Desa Pasauran. Selain itu, mahasiswa KKM juga diharapkan mampu mewujudkan tri darma perguruan tinggi terutama dalam bidang kewirausahaan, pendidikan dan budaya di daerah tersebut.

Pertama, Co-Creation dapat dilaksanakan berdasarkan gagasan bersama sebagai hasil sinkronisasi antara universitas (mahasiswa, dosen) dengan pihak pemerintah daerah, mitra kerja, dan masyarakat setempat. Kedua, cofinancing dapat dilaksanakan dengan pendanaan bersama antara mahasiswa, pelaksana, universitas, pemerintah daerah, serta mitra kerja dalam program yang di sepakati. Ketiga, flexsibility dapat dilaksanakan berdasarkan pada suatu program yang sesuai dengan situasi dan kondisi pemerintah daerah, mitra kerja, dan masyarakat setempat. Keempat, Sustainability dapat dilaksanakan secara berkesinambungan berdasarkan program kerja yang sesuai dengan tempat dan target tertentu. Kelima, lokalitas dapat dilaksanakan berdasarkan dengan kasus yang ada di daerah tertentu. Keenam, Indigenous dapat dilaksanakan berdasarkan karakteristik daerah tersebut. Ketujuh, Competencie dapat dilaksanakan berdasarkan kompetensi mahasiswa dan daerah yang menjadi tempat untuk melaksanakan program-program dan perencanaan-perencanaan yang ada

\section{METODE}

Teknik pengumpulan data merupakan langkah yang paling utama dalam penelitian, karena tujuan utama dari penelitian adalah mendapatkan data. Menurut Sugiyono (2007:209) bila dilihat dari segi cara atau teknik pengumpulan data, maka teknik pengumpulan data dapat dilakukan dengan observasi, wawancara, angket dan dokumentasi. Pada pembuatan laporan kali ini kami menggunakan teknik pengumpulan data menggunakan wawancara, dokumentasi dan observasi. 


\section{HASIL DAN PEMBAHASAN}

\section{Tahapan Persiapan}

pelaksanaan KKM Tematik ini selalu diawali dengan tahapan persiapan, yaitu mempersiapkan calon mahasiswa KKM Tematik dan mempersiapkan pembekalan bagi mahasiswa.
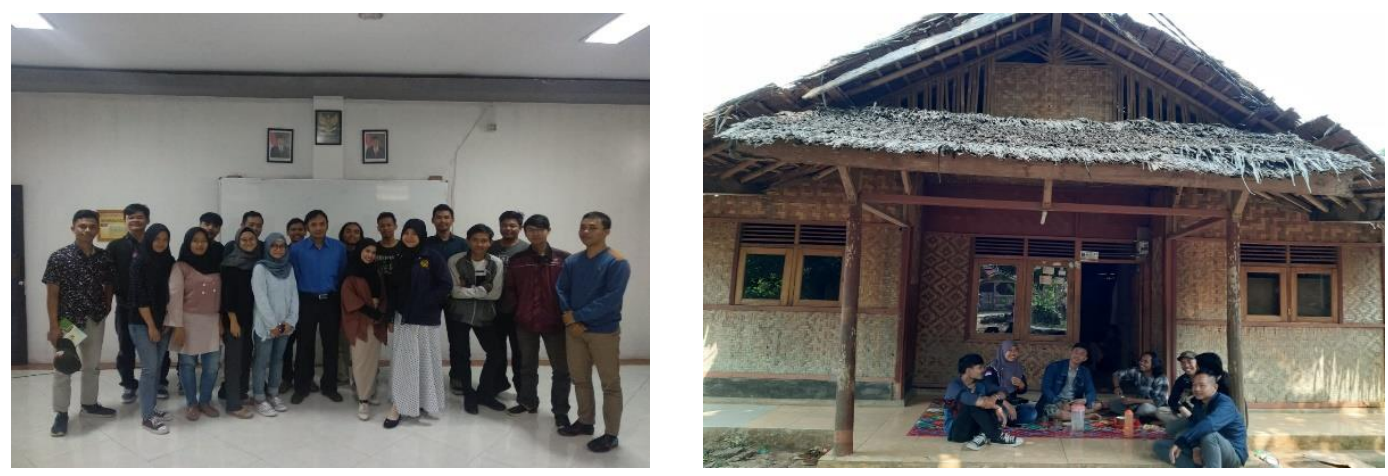

\section{Gambar 1. Tahap Persiapan}

\section{Pembekalan Mahasiswa}

Pelaksanaan pembekalan ini bertujuan untuk mendekatkan pemahaman mahasiswa terhadap kebutuhan tema program yang akan dilaksanakan oleh mahasiswa. Tahapan pembekalan mahasiswa KKM Tematik berdasarkan disesuaikan kebutuhan tema program, yaitu pembekalan materi ilmu terapan sesuai disiplin ilmu masing-masing mahasiswa. Mulai materi umum, materi administrasi, materi kemasyarakatan, materi kewirausahaan, materi kecakapan khusus dan materi manajemen dan program KKM Tematik.
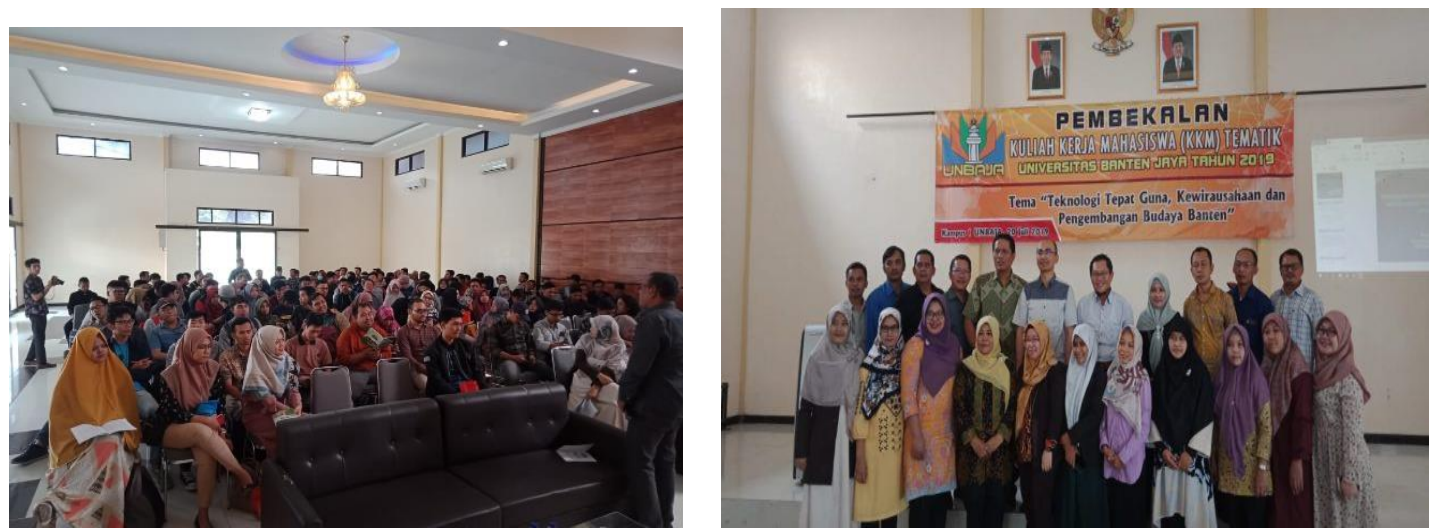

Gambar 2. Tahap Pembekalan 


\section{Pengarahan, Pelepasan dan Serah Terima Mahasiswa}

Pelaksanaan pengarahan, pelepasan dan serah terima mahasiswa ini dimaksudkan untuk pembekalan umum oleh pejabat Rektorat untuk memberikan motivasi, dukungan dan arahan selama pelaksanaan KKM Tematik, diharapkan mahasiswa mampu menjaga diri, bersosialisasi dan bertugas menyelesaikan kegiatan KKM Tematik dengan baik dan benar
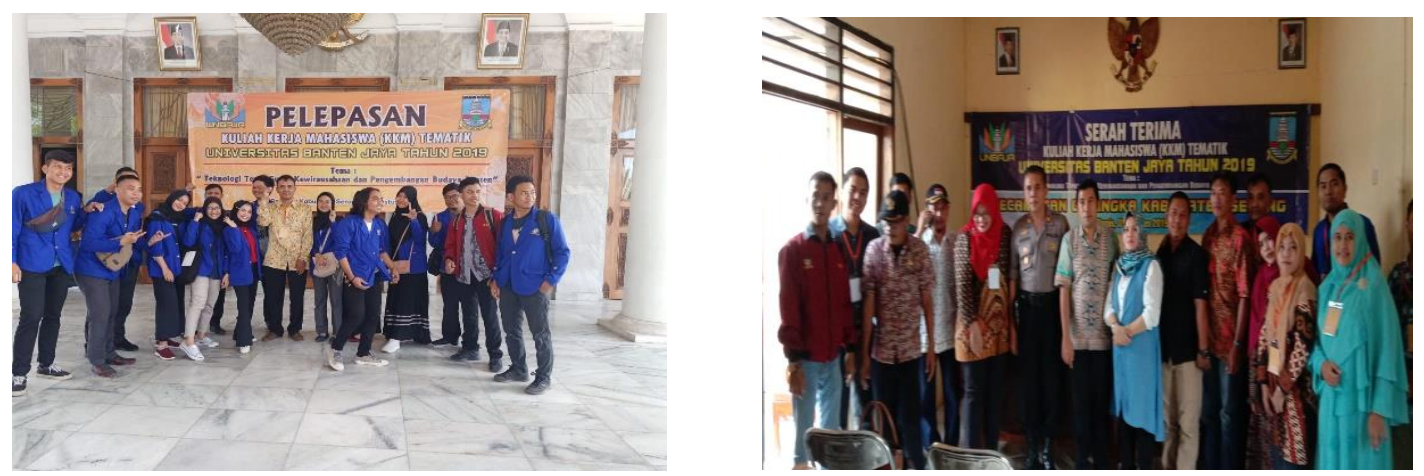

\section{Gambar 3. Tahap Pelepasan}

\section{Tahapan Realisasi Program}

Pelaksanaan KKM tematik telah dilakukankoordinasi dan sosialisasi program- program kepada masyarakat sasaran, yaitu
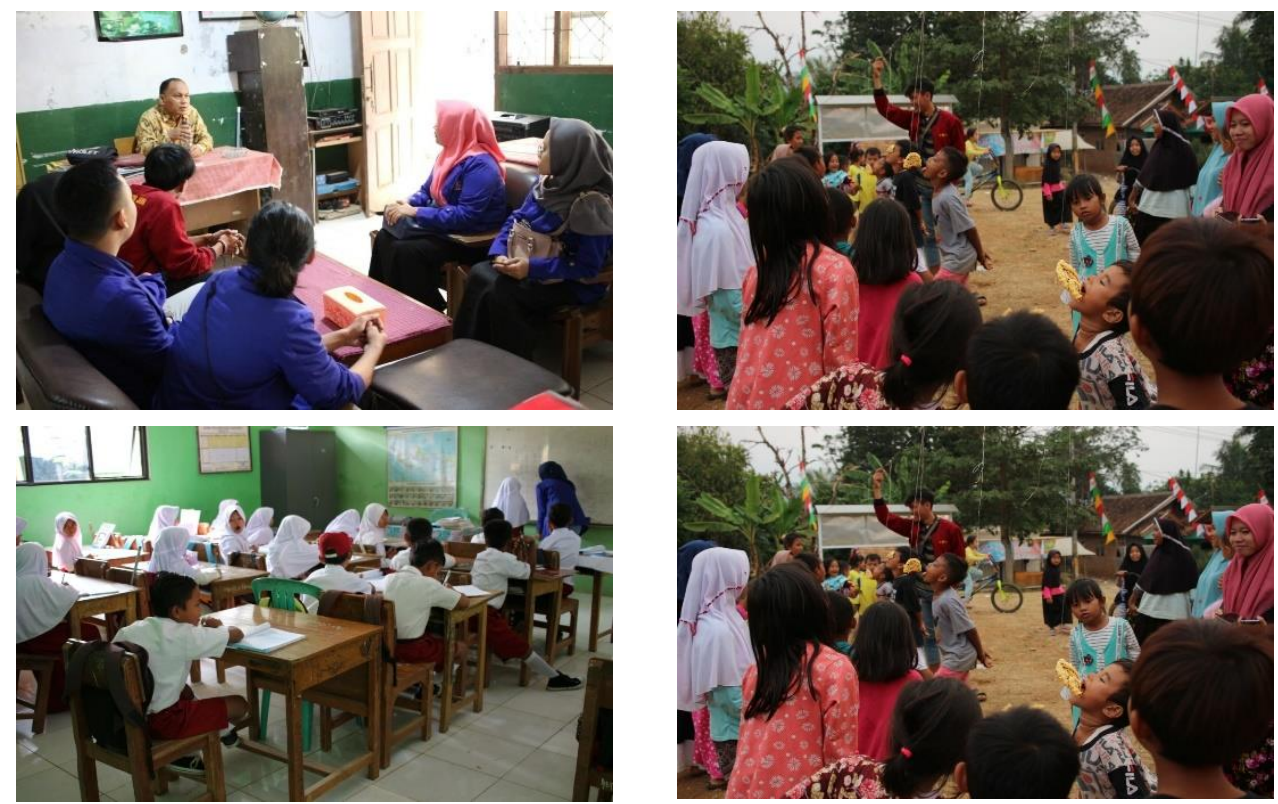

Gambar 4. Program yang Dilaksanakan

\section{Kegiatan Wajib}

1. Bidang Kegiatan yang dipilih

Kegiatan yang di pilih yaitu bersosialisasi tentang mengenalkan sistem Technopreneurship (Penjualan Berbasis Online) dan juga menyelenggarakan seminar tentang technopreneurship. 
2. Maksud, Tujuan, dan Sasaran yang ingin dicapai

Maksud di selenggarakannya seminar tentang Technopreneurship yaitu untuk memasarkan produk yang di produksi oleh masyarakat melalui teknologi. Tujuannya untuk memudahkan masyarakat dalam memasarkan produknya. Dengan melalui pelatihan bagi siswa-siswa SMA PLUS BAITURRAHMAN. Sasaran yang ingin dicapai yaitu masyarakat Kampung Cipanas Girang agar memahami s penjualan di bidang kewirausahaan melalui aplikasi teknologi.

3. Hasil yang dicapai dan Tindak Lanjut

Memudahkan perekonomian masyarakat Kampung Cipanas Girang dan tindak lanjutnya dapat mengembangkan usaha yang di miliki oleh masyarakat setempat.

4. Faktor Pendukung dan Penghambat

Faktor pendukungnya yaitu keinginan masyarakat memproduksi yang akan di pasarkan sangat tinggi, sedangkan faktor pengambatnya yaitu keterbatasan dalam megakses internet, pengemasan (packaging) hasil produk yang kurang menarik dan keterbatasannya peralatan dalam pengemasan produk.

\section{Kegiatan Kelompok}

1. Bidang Kegiatan yang di pilih

1) Kegiatan Gotong Royong Membuat Gapura

2) Memperbaiki Fasilitas Sekolah Dasar Cipanas Girang (Papan Penanda Kelas)

3) Memfasilitasi Tempat Sampah Sementara Untuk Kampung

4) Memperbaiki Plang Sekolah Dasar Cipanas Girang

5) Menyelenggarakan Pelatihan dan Bersosialisasi memperkenalkan Technopreneurship (Penjualan Berbasis Online)

6) Mengajar Siswa-Siswi Sekolah Dasar Cipanas Girang

2. Maksud, Tujuan, dan Sasaran yang ingin dicapai

Maksudnya ingin memfasilitasi Kampung Cipanas Girang dan mengajarkan masyarakat berwirausaha secara online. Tujuannya untuk memperbaiki kebiasaan masyarakat membakar sampah guna mengurangi polusi udara di daerah setempat. Sasaran yang ingin dicapai yaitu memperbaiki kebiasaan masyarakat untuk menjadi lebih baik.

3. Hasil yang Dicapai dan Tindak Lanjut

Hasil yang dicapai yaitu sudah tersedianya fasilitas Gapura Kampung, Tempat Sampah Sementara di Kampung, Papan Penanda Kelas danpara pemuda sudah menjadi kreatif dalam pengembangan kerajinan tangan untuk membantu perekonomian masyarakat di Kampung Cipanas Girang. Tindak lanjut yang dapat dilakukan oleh kelompok kita yaitu mengembangkan yang sudah di ajarkan oleh kita kepada masyarakat demi kesejahteraan dalam bidang perekonomian dan kreatifitas. 
4. Faktor Pendukung dan Penghambat.

Faktor pendukungnya yaitu dari masyarakatnya saling membantu untuk gotong royong menyediakan bahan-bahan yang di perlukan untuk program kerja di Kampung Cipanas Girang. Faktor penghambatnya yaitu waktu yang terbatas, jarak tempuh untuk membeli peralatan yang di butuhkan lokasinya cukup jauh dan kurangnya dukungan dari Dinas terdekat.

\section{Kegiatan Mandiri}

1. Bidang-Bidang Kegiatan

1) Membuat Kerajinan Tangan

2) Mengajarkan Anak-Anak Bermain Alat Musik (Biola, Suling, Gitar)

3) Mengajarkan Permainan Lokal

4) Mengikuti Event Perlombaan Bola Volly antar Kampung

5) Aktif dalam acara Agustusan Kelurahan/Kecamatan

6) Mengikuti Pengajian Rutin

7) Mengikuti Acara Kemasyarakatan

8) Mengikuti Kearifan Lokal

2. Hasil yang di Capai dan Tindak Lanjut

1) Pemuda menjadi kompak dalam menjalankan kegiatan.

2) Anak - anak menjadi tahu permainan Lokal yang saat ini hampir punah.

3) Mahasiswa dan warga menjadi bersinegi dalam mengikuti Event Bola Volly antar Kampung

4) Anak - anak menjadi bisa bermain alat musik

5) Ibu - ibu dan Mahasiswi saling membantu

6) Anak - anak menjadi kreatif membuat suatu kerajinan tangan

7) Mahasiswa saling bergotong royong untuk membenahi Kampung

8) Mahasiswa menjadi tau Adat Istiadat dan Tradisi Kampung

3. Partisipasi Masyarakat dan Peran serta Pemuda/Dinas/Instalasi

Partisipasi Masyarakat dan Peran serta Pemuda/Dinas/Instalasi sangat antusias mendukung setiap kegiatan yang di buat selama berada di Kampung, dengan dukungan, tenaga, materi, serta Doa yang tidak senantiasa terputus sehingga terlaksananya sebuah Kegiatan yang sangat bermanfaat bagi warga Kampung setempat dan bisa di terapkan di suatu hari nanti untuk kebaikan bersama.

4. Kegiatan yang belum terlaksana

Adapun Kegiatan yang belum terlaksana yaitu membuat Tempat Sampah yang dapat di gunakan secara berkepanjangan atau Permanen, karena keterbatasan lahan untuk 
membangunnya Tempat Sampah di Kampung tersebut. Selain itu Warga di Kampung selalu mengatasi sampah dengan membakar sampah tersebut, sulit bagi kita menyediakan Tempat Sampah yang layak untuk digunakan.

\section{KESIMPULAN}

Pelaksanaan program KKM tematik Desa Pasauran Kecamatan Cinangka, Kabupaten Serang, Provinsi Banten ini mendapatkan respon yang positif dari masyarakat dan pemerintah Sejatinya sebagai Mahasiswa menerapkan TRI DHARMA PERGURUAN TINGGI di dalamnya Mahasiswa berkewajiban Mengabdi kepada Masyarakat guna mengembangkan pengetahuan yang kurang dan terbatas, memajukan suatu Perkampungan dari keterbatasan pengetahuan. Untuk itu terlaksananya Kuliah Kerja Mahasiswa (KKM) untuk menerapkan bagaimana caranya mengabdi kepada Masyarakat setempat, dengan pengetahuan yang dimiliki Mahasiswa di dalam Akademik. Dengan membuat suatu Kegiatan yang berisi Ilmu Pengetahuan yang bermanfaat bagi masyarakat setempat, guna membangkitkan semangat untuk membenahi keterbatasan berfikir masyarakat dalam memajukan Desa Pasauran Kecamatan Cinangka, Kabupaten Serang, Provinsi Banten.

\section{UCAPAN TERIMAKASIH}

Ucapan Terima kasih kami sampaikan kepada masyarakat Desa Pasauran Kecamatan Cinangka, Kabupaten Serang, Provinsi Banten kegiatan pelaksanaan Pengabdian masyarakat KKM Tematik Universitas Banten Jaya pada bulan Agustus tahun 2019.

\section{DAFTAR PUSTAKA}

Soekadijo. (1997). Anatomi Pariwisata: Memahami Pariwisata sebagai System Linkage. Jakarta: PT Gramedia Pustaka Utama.

Sugiantoro, V, R. (2000). Pariwisata: Antara Realisasi dan Realita. Yogyakarta: Adi Cita Karya Nusa.

Wahab, S. (1996). Manajemen Kepariwisataan. Jakarta: PT Pradya Paramita. 